\title{
Dinâmica dos Nutrientes no Trato Gastrintestinal de Novilhos Holandeses Alimentados com Dietas à Base de Cana-de-Açúcar
}

\author{
Elzânia Sales Pereira ${ }^{1}$, Augusto César de Queiroz ${ }^{2}$, Mario Fonseca Paulino², Sebastião de \\ Campos Valadares Filho ${ }^{2}$, Alex Martins Varela de Arruda ${ }^{1}$, Luciano da Silva Cabral ${ }^{3}$, \\ Lídia Ferreira Miranda ${ }^{4}$, Alberto Magno Fernandes ${ }^{5}$
}

\begin{abstract}
RESUMO - Foram objetivos deste trabalho validar as predições com base nas estimativas da dinâmica ruminal e pós-ruminal dos nutrientes e do crescimento microbiano no rúmen, usando as equações que compõem o submodelo Cornell relativo ao trato gastrintestinal. Foram utilizados quatro novilhos Holandês-Zebu com peso médio de 300 kg, canulados no rúmen e abomaso, distribuídos em delineamento quadrado latino 4 x 4 . Os animais experimentais foram alimentados com rações à base de cana-de-açúcar, suplementada com duas fontes de nitrogênio (uréia ou cama de frango) e dois níveis de levedura (0 ou $10 \mathrm{~g} \mathrm{dia}^{-1}$ ), constituindo-se esquema fatorial 2 x 2 . A FDN indigestível e a FDN da cana-de-açúcar complexada com cromo foram usadas como indicadores interno e externo, para estimar a produção fecal diária e a taxa de passagem de partículas no rúmen. A dinâmica dos nutrientes baseou-se nas determinações do fluxo de nitrogênio total e do fluxo de nitrogênio de origem bacteriana no abomaso e dos carboidratos totais digeridos no rúmen. A produção microbiana não foi influenciada pelas fontes nitrogenadas e pela adição de Saccharomyces cerevisiae. O Sistema Cornell superestimou os carboidratos totais degradados no rúmen, o fluxo de nitrogênio de origem microbiana e subestimou o fluxo de $\mathrm{N}$ total no abomaso.
\end{abstract}

Palavras-chave: eficiência microbiana, sistema CNCPS, taxa de passagem

\section{Dynamic of the Nutrients in the Gastrintestinal Tract of Holstein Steers Fed Sugar Cane Based Diets}

\begin{abstract}
The objectives of this work were to validate the predictions based on the estimates of the ruminal nutrient dynamics and on the microbial growth in the rumen, using equations of the Cornell Submodel system relative to the gastrintestinal tract. Four Holstein - Zebu steers, with $300 \mathrm{~kg}$ live weight, rumen and abomasal cannulated were allotted to 4x4 latin square design. The experimental animals received sugar cane based diets, supplemented with two nitrogen sources (urea or poultry litter) and two yeast levels (0 or 10 $\mathrm{g} / \mathrm{d}$ ), being constituted 2x2 factorial arrangement. The indigestible neutral detergent fiber (NDF) and chromium mordant sugar cane NDF were used as internal and external markers to estimate the daily fecal production and the ruminal particle passage rates. The dynamics of the nutrients was based on the determination of the total nitrogen and the abomasal nitrogen flows of microbial origin and total carbohydrate digested in the rumen. The microbial yield was not influenced by nitrogen sources or by Saccharomyces cerevisiae. The Cornell system overestimated the total ruminal carbohydrates digestion and the nitrogen flow of microbial origin and underestimated total nitrogen flow in the abomasum.
\end{abstract}

Key Words: microbial efficiency, CNCPS system, rate of passage, ruminant nutrition

\section{Introdução}

Em grande parte do território nacional, os bovinos leiteiros de médio potencial de produção são alimentados com dietas à base de cana-de-açúcar. O emprego racional da cana-de-açúcar como alimento justifica-se por várias razões: elevada produção por unidade de área cultivada, cultivo relativamente fácil, baixo custo por unidade de matéria seca produzida e coincidência do período de sua maior disponibilidade com o período de escassez de forragens na forma de pasto.

No entanto, a cana-de-açúcar, como alimento para ruminantes, apresenta limitações de ordem nutricional, devido aos baixos teores protéicos; variações nas frações nitrogenadas; frações relativamente altas de carboidratos estruturais; alta fração C (fração indigestível durante sua permanência no trato digestório); menor taxa de crescimento específico de microrganismos ruminais, responsáveis pela baixa degradação; e aumento do efeito de repleção ruminal

\footnotetext{
${ }^{1}$ Professor do curso de Zootecnia da Universidade Estadual do Oeste do Paraná- UNIOESTE - PR. E.mail: elzania@hotmail.com

2 Professores do Departamento de Zootecnia da Universidade Federal de Viçosa - UFV - MG.

3 Professor da Universidade Federal do Mato Grosso - MT.

${ }^{4}$ Professor da FEAD-MG.

5 Professor da Universidade Estadual do Norte Fluminense - UENF, Campos dos Goytacazes, RJ.
} 
da FDN desse alimento (Pereira et al., 2000).

Os animais consomem o alimento principalmente para atender suas exigências em energia, além de outros nutrientes necessários. Entretanto, se por alguma razão a natureza do volumoso disponível restringe o consumo alimentar, o desempenho animal ficará limitado, cuja conseqüência direta é a redução na eficiência do processo produtivo.

As exigências protéicas dos ruminantes são atendidas mediante a absorção intestinal de aminoácidos provenientes da proteína microbiana sintetizada no rúmen e da proteína dietética não-degradada no rúmen (Valadares Filho, 1995). A quantificação da proteína microbiana que chega ao intestino delgado pode ser obtida a partir do conhecimento da eficiência de síntese microbiana, definida como a proporção do substrato energético, que é fixado como célula microbiana (Dehority, 1995). A otimização da fermentação e a maximização da eficiência de síntese microbiana poderão, portanto, ser obtidas por intermédio da manipulação de componentes dietéticos. A disponibilidade de energia e compostos nitrogenados são os principais determinantes do processo de síntese microbiana no rúmen, e os carboidratos estruturais e não-estruturais são as melhores fontes energéticas para o crescimento microbiano (Clark et al., 1992).

Os sistemas para avaliação de alimentos e determinação das exigências nutricionais dos ruminantes tratam de forma diferente as porções dos alimentos que constituem as fontes de energia para esses animais. O conteúdo em energia metabolizável fermentescível de um alimento é utilizado no sistema AFRC (1993), para estimar o crescimento microbiano e, conseqüentemente, a contribuição da proteína microbiana em aminoácidos para o hospedeiro. Seu cômputo baseia-se no conteúdo em energia metabolizável do alimento, descontando-se a contribuição em energia metabolizável do extrato etéreo; no caso das silagens, desconta-se também a contribuição em energia metabolizável dos ácidos orgânicos. O teor em nutrientes digestíveis totais (NDT) é utilizado para calcular a eficiência de crescimento microbiano no sistema National Research Council (NRC, 1989). Entretanto, nesse sistema, não são consideradas as inter-relações dinâmicas do ecossistema ruminal (Russell et al., 1992; NRC, 1996).

O sistema Cornell Net Carbohydrate and Protein System-CNCPS expressa a eficiência microbiana em gramas de MS microbiana (gMSbac) por grama de carboidratos totais degradados no rúmen, em razão destes serem as fontes primárias de energia para o crescimento dos microrganismos (Russell et al., 1992).

Aumentos no consumo proporcionam maior escape de $\mathrm{N}$ microbiano e $\mathrm{N}$ dietético para o duodeno, possivelmente, em virtude do aumento nas taxas de passagem e diluição (Van Soest, 1994). No entanto, incremento apenas nos níveis de consumo de PB resultou em aumento no fluxo de $\mathrm{N}$ amoniacal (Nolan, 1993) e no escape de PNDR, uma vez que o $\mathrm{N}$ microbiano é mais dependente da ingestão de energia (Clark et al., 1992). O crescimento microbiano no rúmen é influenciado pela interação de fatores químicos, fisiológicos e nutricionais (Van Soest, 1994). A qualidade e a quantidade dos produtos de fermentação são dependentes do tipo e da atividade dos microrganismos que compõem a população, que, por sua vez, dependem da dieta. O CNCPS separa os microrganismos ruminais em dois grupos: aqueles que fermentam carboidratos estruturais apresentam crescimento lento e utilizam amônia como fonte de nitrogênio para o processo de síntese de microbiana, não fermentando peptídeos ou aminoácidos, e os que fermentam carboidratos não-estruturais têm crescimento mais rápido, utilizam amônia, peptídeos e aminoácidos, como fonte de nitrogênio, além de produzirem amônia.

Este sistema foi desenvolvido com o objetivo de avaliar dietas completas, minimizar a excreção de nutrientes, maximizar a sincronização de carboidratos e proteína no rúmen e, conseqüentemente, a produção máxima do crescimento microbiano (Russell et al., 1992; Van Soest, 1994).

O modelo de Cornell tem sido utilizado para avaliar dietas com base em feno e silagem para animais em crescimento (Fox et al., 1995) e não inclui volumosos de baixo valor nutricional. O submodelo relativo ao trato gastrintestinal permite testar quaisquer tipos de dietas balanceadas e desenvolver estratégias que possibilitem a melhor utilização dos alimentos; sendo composto por equações que, a partir de determinações com base em métodos químicos e biológicos, permitem estimar a dinâmica ruminal e pós-ruminal dos nutrientes dietéticos, o crescimento microbiano no rúmen e, conseqüentemente, o aporte de energia e proteína metabolizáveis para o hospedeiro (Russell et al., 1992; Sniffen et al., 1992; Vieira, 1998).

Em virtude da importância da cana-de-açúcar como fonte de energia para animais no Brasil, tornam-se necessários estudos para verificar a exatidão 
das estimativas desse modelo e sua aplicabilidade em várias condições de alimentação e manejo. A melhor forma de averiguar a aplicabilidade do CNCPS consiste na comparação dos valores preditos com as estimativas obtidas no sistema real, in vivo (Vieira, 1998).

O presente estudo foi conduzido com o objetivo de estimar a dinâmica dos nutrientes no rúmen e intestinos e validar as predições dessas estimativas utilizando as equações que compõe o submodelo relativo ao trato gastrintestinal do CNCPS.

\section{Material e Métodos}

O experimento foi realizado nos Laboratórios de Animais e de Nutrição do Departamento de Zootecnia da Universidade Federal de Viçosa.

Foram utilizados quatro novilhos mestiços Holandês-Zebu, com idade de 18 meses e peso médio de $300 \mathrm{~kg}$, canulados no rúmen e abomaso.

Os animais foram mantidos em regime de confinamento, alojados em baias individuais cobertas de $3 \mathrm{~m} \mathrm{x} 3 \mathrm{~m}$ de área, com piso e comedouro de concreto e bebedouros automáticos.

Os tratamentos foram constituídos de cana-deaçúcar (Saccharum ssp, L.), suplementada com duas fontes nitrogenadas - uréia e cama de frango (em substituição parcial da uréia), com ou sem adição de Saccharomyces cerevisiae.

A mistura concentrada foi composta de uréia, farelo de algodão, fosfato bicálcico, calcário e sal. As rações foram balanceadas conforme as exigências estabelecidas pelo NRC (1989). A especificação da composição bromatológica da cultura de levedura utilizada, YEA-SACC1026 -Alltech, foi 89,2\% MS; 33,7\% PB; 6,7\% EE; 15,6\% FDA; 9,4\% MM; 0,26\% Ca; 1,16\% P; 0,63\% S; 0,49\%Mg; 0,18\% Na; 436 ppm Fe; 46 ppm Mn; 19 ppm Cu; e 700 ppm Zn, com $106 \mathrm{UFC} / g$. O delineamento experimental utilizado foi quadrado latino $4 \times 4$, em esquema fatorial ( $2 \times 2$ ), no qual os fatores foram as duas fontes de NNP e os dois níveis de suplementação com Saccharomyces cerevisiae. Os fluxos de matéria seca abomasal e fecal foram estimados utilizando-se o teor de FDN indigestível in situ, nas amostras dos alimentos, do abomaso, das fezes e sobras, cujas amostras foram incubadas no rúmen em saco de náilon, por 144 horas, segundo a metodologia descrita por Cochran et al. (1986). Os teores de fibra em detergente neutro na matéria seca dos alimentos e na matéria seca abomasal e fecal foram determinados de acordo com os proce- dimentos descritos por Van Soest et al. (1991).

Os quatro períodos experimentais tiveram duração de 22 dias, sendo 10 dias de adaptação às dietas e quatro dias para coletas de fezes e digesta de abomaso; após três dias, do $17 \underline{0}$ dia ao $21^{\circ}$ ㅁ dia, foram determinadas as taxas de passagem da FDN da canade-açúcar. No $22^{\circ}$ dia cada período experimental, aproximadamente $1,5 \mathrm{~L}$ de conteúdo ruminal de cada animal foram coletados, para isolamento de bactérias, conforme técnica descrita por Cecava et al. (1990). Com este procedimento, foi obtida uma amostra composta por tratamento. As bases purinas foram utilizadas como indicador, para estimar a produção microbiana, e analisadas conforme metodologia de Ushida et al. (1985).

A ração total foi fornecida à vontade, uma vez ao dia, às $8 \mathrm{~h}$, tendo sido as sobras previamente pesadas e amostradas para determinação do consumo diário. A quantidade de ração fornecida foi calculada de modo a permitir sobras de aproximadamente $10 \%$ do total fornecido. Foram realizadas amostras compostas de cana-de-açúcar, cama de frango e concentrados fornecidos e das sobras por animal em cada período. Todas estas amostras foram devidamente armazenadas a $-5^{\circ} \mathrm{C}$, posteriormente moídas em moinho com peneira de $1 \mathrm{~mm}$ e submetidas às análises laboratoriais. A determinação da composição bromatológica, ou seja, dos diferentes compostos nitrogenados, carboidratos, lignina, extrato etéreo e matéria mineral, foram obtidas de acordo com os procedimentos descritos por Pereira et al. (2000).

A quantificação dos compostos nitrogenados não-amoniacais (NNA) na digesta de abomaso foi obtida por diferença entre o nitrogênio total e o NNH3 determinado em amostras in natura dos líquidos de abomaso, após centrifugação. Os dados de consumo e digestibilidade foram avaliados por meio de análise de variância, utilizando-se o programa SAEG (UFV, 1995).

As taxas de passagem relativas às amostras de cana-de-açúcar, obtidas para cada animal, nos respectivos períodos experimentais, foram estimadas mediante o uso do dicromato de potássio complexado á FDN, conforme metodologia de Úden et al. (1980). As amostras de cana-de-açúcar complexadas com cromo foram fornecidas aos animais, 15 minutos antes da alimentação, via cânula ruminal, em dose única, acondicionadas em cápsulas de papel. Coletaram-se, aproximadamente, $200 \mathrm{~g}$ de fezes nos intervalos de tempo 0; 12; 16; 24; 30; 36; 48; 72; 96; e 120 h 
pós-dosagem (Gomes, 1991). A taxa de passagem foi estimada pelo modelo de Grovum e Williams (1973), ajustado pelo PROC NLIN do SAS (1985).

A validação das predições relativas à dinâmica ruminal e pós-ruminal dos nutrientes foi realizada por meio da regressão dos valores calculados sobre os valores observados dos fluxos de nitrogênio total (g/d), do nitrogênio de origem bacteriana no abomaso (g/d) e das digestibilidades ruminais dos carboidratos totais (g/d).

As estimativas dos parâmetros das equações de regressão foram testadas pelas hipóteses $\mathrm{H}_{0}^{(\mathrm{a})}: \beta_{0}=0$ e $\mathrm{H}_{0}^{(\mathrm{b})}: \beta_{1}=1$, o que permitiu identificar se o modelo Cornell superestimou ou subestimou os valores preditos em relação aos valores observados. O vício das estimativas foi calculado ao multiplicar por 100 o coeficiente angular do modelo $Y=\beta_{1} X$, em que $\mathrm{Y}$ corresponde aos valores observados e $\mathrm{X}$, aos valores preditos (O'Connor et al., 1993). O ajuste dos dados foi feito utilizando o PROC REG do SAS (1985).

\section{Resultados e Discussão}

As médias das frações nitrogenadas e dos carboidratos dos alimentos, bem como os parâmetros relacionados à cinética de degradação, encontram-se em Pereira et al. (2000). Na Tabela 1, está expressa a composição bromatológica das rações experimentais.

A composição das bactérias ruminais observada na Tabela 2 mostra que a média de 5,54\%, obtida para $\mathrm{N}$-total entre os tratamentos, foi inferior aos valores de 7,71 e 7,10\% de N-total, obtidos a partir de dados compilados da literatura e relatados por Clark et al. (1992) e Valadares Filho (1995), respectivamente. Esses autores citaram valores médios de 13,7 e 17,8\% para a relação N-RNA: N-total, porém, no presente estudo, esta relação mostrou-se muito variável, apresentando valor médio de 18,37\%. Dessa forma, em virtude da variação encontrada para a relação N-RNA:N total nos diferentes tratamentos, decidiu-se usar a relação média obtida para os tratamentos 2 e 3, de 11,87\%, para calcular a produção microbiana em todos os tratamentos (Tabela 3). Esta média (11,87\%) está próxima ao valor sugerido por Chen \& Gomes (1992), de 11,6\%. As bactérias ruminais geralmente apresentam 50\% de proteína bruta, 23\% de ácidos nucléicos, 9\% de lipídeos e 18\% de carboidratos. No entanto, esta composição pode ser alterada em face das condições limitantes do meio (Nocek \& Russell, 1988). Esses autores sugeriram que as estimativas do rendimento microbiano sejam expressas com base no teor de $\mathrm{N}$ bacteriano, em vez do peso seco de células.

Na Tabela 3, estão expressas as estimativas da dinâmica dos nutrientes no trato gastrintestinal (valores observados nos animais).

O aumento no consumo de $\mathrm{N}(\mathrm{P}<0,05)$ das dietas suplementadas com cama de frango proporcionou maiores fluxos de $\mathrm{N}$ total e NNA para o abomaso. Os fluxos de $\mathrm{N}$ bacteriano não variaram entre os tratamentos, apresentando valor médio de 62,76 g/dia. Esse comportamento indica que os aumentos detectados nos fluxos de NNA verificados foram atribuídos ao maior escape de proteína dietética não-degradada no rúmen. Estes resultados estão coerentes com as observações de Clark et al. (1992), os quais concluíram que aumentos no consumo de proteína estão relacionados a incrementos nos fluxos de PNDR para o abomaso. Esses autores também afirmaram que os aumentos nos consumos de MS estão relacionados aos maiores fluxos de $\mathrm{N}$ bacteriano para $\mathrm{o}$ abomaso, o que não foi verificado neste estudo.

O fluxo de $\mathrm{N}$ bacteriano representou, em média, $39,91 \%$ do fluxo de NNA abomasal nos diversos tratamentos.

Não foi detectado efeito do uso de Saccharomyces cerevisiae, bem como sua interação com as fontes de nitrogênio sobre as variáveis estudadas. Não se observou também efeito das dietas experimentais sobre o rendimento microbiano, quando o mesmo foi expresso em g N/kg CTDR, g MSmic/kg CTDR, e g Pbmic/100 g NDT, cujos valores médios foram 29,08; 510,36; e 18,43, respectivamente(Tabela 3).

$\mathrm{Na}$ Tabela 4, estão expressas as estimativas das taxas de passagem das partículas da cana-de-açúcar, no rúmen-retículo e no ceco-colón proximal, o tempo de retenção no rúmen retículo, o tempo de retenção no ceco-cólon proximal e o tempo médio de retenção nos dois compartimentos. Os valores obtidos para a taxa de passagem ruminal neste estudo, para animais em mantença, foram semelhantes à taxa reportada pelo ARC (1984) de $2 \% \mathrm{~h}^{-1}$. Como digestibilidade e taxa de passagem podem ser, ao mesmo tempo, efeito e causa do pool de nutrientes disponíveis aos animais, o fato de não ter havido diferença entre taxas de passagem das partículas nos dois compartimentos, provavelmente, pode ser apontado como responsável por não terem sido encontradas diferenças entre os 
Tabela 1 - Porcentagem dos ingredientes e composição bromatológica das rações

Table 1 - Percentage of the ingredients and chemical composition of the diets

\begin{tabular}{|c|c|c|c|c|}
\hline \multirow[t]{2}{*}{ Item } & \multicolumn{4}{|c|}{$\begin{array}{l}\text { Tratamento } \\
\text { Treatment }\end{array}$} \\
\hline & $\begin{array}{l}\text { Cana-de-açúcar+ } \\
\text { uréia } \\
\text { S.cerevisiae } \\
\end{array}$ & $\begin{array}{l}\text { Cana-de-açúcar+ } \\
\text { uréia }\end{array}$ & $\begin{array}{l}\text { Cana-de-açúcar+ } \\
\text { cama de frango }\end{array}$ & $\begin{array}{l}\text { Cana-de-açúcar+ } \\
\text { cama de frango } \\
\text { S.cerevisiae }{ }^{1}\end{array}$ \\
\hline \multicolumn{5}{|l|}{$\begin{array}{l}\text { Ingrediente (\%) } \\
\text { Ingredient (\%) }\end{array}$} \\
\hline $\begin{array}{l}\text { Cana-de-açúcar } \\
\text { Sugar cane }\end{array}$ & 82,53 & 82,53 & 60,14 & 60,14 \\
\hline $\begin{array}{l}\text { Cama de frango } \\
\text { Broiler litter }\end{array}$ & - & - & 28,74 & 28,74 \\
\hline $\begin{array}{l}\text { Farelo de algodão } \\
\text { Cottonseed meal }\end{array}$ & 14,68 & 14,68 & 9,11 & 9,11 \\
\hline $\begin{array}{l}\text { Uréia /Sulfato de amônia (9:1) } \\
\text { Urea/Ammonia sulfate (9:1) }\end{array}$ & 1,62 & 1,62 & 0,91 & 0,91 \\
\hline $\begin{array}{l}\text { Fosfato bicálcico } \\
\text { Dicalcium phosphate }\end{array}$ & 0,42 & 0,42 & 0,37 & 0,37 \\
\hline $\begin{array}{l}\text { Calcário } \\
\text { Limestone }\end{array}$ & 0,56 & 0,56 & 0,53 & 0,53 \\
\hline $\begin{array}{l}\text { Sal } \\
\text { Salt } \\
\text { Composição bromatológica (g }\end{array}$ & 0,19 & 0,19 & 0,19 & 0,19 \\
\hline Chemical composition & & & & \\
\hline $\begin{array}{l}\text { Lignina } \\
\text { Lignin }\end{array}$ & 62,89 & 62,89 & 81,40 & 81,40 \\
\hline $\mathrm{FDN}_{\mathrm{cp}}{ }^{2}$ & 503,8 & 503,8 & 489,2 & 489,2 \\
\hline $\begin{array}{l}\mathrm{CS}^{3}{ }^{a p} \\
S C\end{array}$ & 72,98 & 72,98 & 57,9 & 57,9 \\
\hline $\begin{array}{l}\mathrm{PB}^{4} \\
\mathrm{CP}\end{array}$ & 111,5 & 111,5 & 128,7 & 128,7 \\
\hline $\begin{array}{l}\mathrm{PS}^{5} \\
S P\end{array}$ & 27,77 & 27,77 & 28,07 & 28,07 \\
\hline $\begin{array}{l}\mathrm{NNP}^{6} \\
N P N\end{array}$ & 24,18 & 24,18 & 21,81 & 21,81 \\
\hline $\begin{array}{l}\text { PIDN }^{7} \\
N D I P\end{array}$ & 6,30 & 6,30 & 23,30 & 23,30 \\
\hline $\begin{array}{l}\text { PIDA }^{8} \\
A D I P\end{array}$ & 2,84 & 2,84 & 7,53 & 7,53 \\
\hline
\end{tabular}

$110 \mathrm{~g}$ de Saccharomyces cerevisiae/anim/•dia (10 g of Saccharomyces cerevisiae/anim/day).

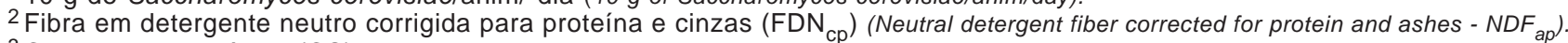

${ }^{3}$ Carboidratos solúveis (CS) (Soluble carbohydrates - SC).

${ }^{4}$ Proteína bruta (PB) (Crude protein - CP).

${ }^{5}$ Proteína solúvel (PS) (Soluble protein - SP).

${ }^{6}$ Nitrogênio não-protéico (NNP) (Non protein nitrogen - NNP).

7 Proteína insolúvel em detergente neutro (PIDN) (Neutral detergent insoluble protein - NDIP).

${ }^{8}$ Proteína insolúvel em detergente ácido (PIDA) (Acid detergent insoluble protein - ADIP). 
Tabela 2 - Teores médios de matéria seca (MS), extrato etéreo (EE), matéria orgânica (MO), N-total (\%MS), N-total (\%MO), N-RNA e relação N-RNA/NTotal das bactérias ruminais

Table 2 - Average values of dry matter (DM), ether extract (EE), organic matter (OM), total-N (\%DM), total-N (\%OM), N-RNA and $N-R N A / N t o t a l$ of the ruminal bacteria

\begin{tabular}{|c|c|c|c|c|}
\hline \multirow[t]{2}{*}{ Item } & \multicolumn{4}{|c|}{$\begin{array}{c}\text { Tratamento } \\
\text { Treatment }\end{array}$} \\
\hline & $\begin{array}{c}\text { Cana-de-açúcar+ } \\
\text { uréia } \\
\text { S.cerevisiae }^{1}\end{array}$ & $\begin{array}{c}\text { Cana-de-açúcar+ } \\
\text { uréia }\end{array}$ & $\begin{array}{l}\text { Cana-de-açúcar+ } \\
\text { cama de frango }\end{array}$ & $\begin{array}{c}\text { Cana-de-açúcar+ } \\
\text { cama de frango } \\
\text { S.cerevisiae }^{1}\end{array}$ \\
\hline MS & 90,95 & 91,75 & 90,46 & 94,81 \\
\hline $\mathrm{EE}^{2}$ & 1,53 & 1,54 & 1,16 & 2,22 \\
\hline $\mathrm{MO}^{2}$ & 53,93 & 45,40 & 54,24 & 55,31 \\
\hline N-TOTAL ${ }^{2}$ & 5,24 & 5,36 & 5,82 & 5,75 \\
\hline N-TOTAL ${ }^{3}$ & 9,72 & 11,80 & 10,73 & 10,39 \\
\hline N-RNA & 1,46 & 0,59 & 0,73 & 1,22 \\
\hline N-RNA/NTotal & 27,86 & 11,07 & 12,67 & 21,26 \\
\hline
\end{tabular}

MS, EE e MO (DM, EE and OM).

$110 \mathrm{~g}$ de Saccharomyces cerevisiae/animal/d.

$2 \%$ na MS (\%DM).

$3 \% \mathrm{MO}(\% \mathrm{OM})$.

Tabela 3 - Estimativas da dinâmica dos nutrientes (valores observados)

Table 3 - Estimate of dietary nutrient dynamics (observed values)

\begin{tabular}{|c|c|c|c|c|c|c|c|}
\hline \multirow[t]{2}{*}{ Item } & \multicolumn{2}{|c|}{$\begin{array}{l}\text { Fonte } \mathrm{N} \\
N \text { source }\end{array}$} & \multicolumn{3}{|c|}{ S. cerevisiae } & \multicolumn{2}{|c|}{$\begin{array}{c}\text { Níveis de significância } \\
\text { Level of significance }\end{array}$} \\
\hline & $\begin{array}{l}\text { Uréia } \\
\text { Urea }\end{array}$ & $\begin{array}{c}\text { Cama de frango } \\
\text { Broiler litter }\end{array}$ & $0 \mathrm{~g} / \mathrm{d}$ & $10 \mathrm{~g} / \mathrm{d}$ & Fonte & $\begin{array}{l}\text { Sac. } \\
\text { Source }\end{array}$ & $\begin{array}{l}\mathrm{CV} \\
(\%)\end{array}$ \\
\hline $\begin{array}{l}\text { Consumo MS } 1 \\
\text { Dry matter intake }\end{array}$ & 5950 & 7300 & 6530 & 6640 & & & 15,99 \\
\hline $\begin{array}{l}\text { Consumo de } \mathrm{N}^{1} \\
N \text { intake }\end{array}$ & $115,59^{b}$ & $149,51^{\mathrm{a}}$ & 130,05 & 127,04 & 0,02393 & & 13,43 \\
\hline $\begin{array}{l}\text { Fluxo N total } \\
\text { Total } N \text { flow }\end{array}$ & $132,26^{b}$ & $197,07^{\mathrm{a}}$ & 161,76 & 167,57 & 0,01500 & & 23,53 \\
\hline $\begin{array}{l}\text { Fluxo de NNA } \\
\text { NAN flow }\end{array}$ & $124,75^{b}$ & $189,77^{a}$ & 154,91 & 159,62 & 0,01250 & & 23,49 \\
\hline $\begin{array}{l}\text { Fluxo N bact. }{ }^{1} \\
\text { Bact } N \text { flow }\end{array}$ & 64,36 & 61,47 & 59,30 & 65,93 & & & 28,73 \\
\hline $\begin{array}{l}\mathrm{CTDR}^{1,2} \\
\text { RDTC }\end{array}$ & 2246 & 2219 & 2377 & 2088 & & & 52,27 \\
\hline $\begin{array}{l}\mathrm{NDT}^{3} \\
T D N\end{array}$ & 3240 & 3270 & 3100 & 3360 & & & 38,56 \\
\hline $\begin{array}{l}\text { Rendimento } \\
\text { Yield }\end{array}$ & 27,89 & 31,13 & 27,10 & 31,02 & & & 38,56 \\
\hline $\begin{array}{l}\text { Rendimento } \\
\text { Yield }\end{array}$ & 546,86 & 516,80 & 428,65 & 549,14 & & & 45,24 \\
\hline $\begin{array}{l}\text { Rendimento }{ }^{6} \\
\text { Yield }\end{array}$ & 20,87 & 16,09 & 18,31 & 18,47 & & & 38,20 \\
\hline 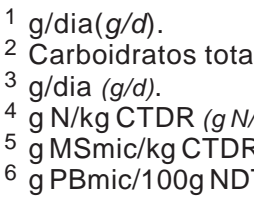 & $\begin{array}{l}\text { DTC). } \\
\text { (TDN). }\end{array}$ & ) (Ruminal degra & & & )- - /dia & & \\
\hline
\end{tabular}


Tabela 4 - Taxa de passagem da cana-de-açúcar no rúmen $\left(k_{1}\right)$ e nos intestinos $\left(k_{2}\right)$, tempo médio de retenção das partículas no rúmen $\left(T M R_{r}\right)$ e nos intestinos $\left(T M R_{i}\right)$ e relação $T M R_{r} / T M R_{i}$

Table 4 - Passage rate of the sugar cane in the rumen $\left(k_{1}\right)$ and in the intestines $\left(k_{2}\right)$, retention time of particulate in the rumen (RMT $\left.T_{r}\right)$ and in the intestines $\left(R M T_{i}\right)$, and $R M T_{r} / R M T_{r}$ ratio

\begin{tabular}{lcccc}
\hline Item & \multicolumn{3}{c}{$\begin{array}{c}\text { Tratamento } \\
\text { Treatment }\end{array}$} \\
\cline { 2 - 5 } & $\begin{array}{c}\text { Cana-de-açúcar+ } \\
\text { uréia } \\
\text { S.cerevisiae }\end{array}$ & $\begin{array}{c}\text { Cana-de-açúcar+ } \\
\text { uréia }\end{array}$ & $\begin{array}{c}\text { Cana-de-açúcar+ } \\
\text { cama de frango }\end{array}$ & $\begin{array}{c}\text { Cana-de-açúcar+ } \\
\text { cama de frango } \\
\text { S.cerevisiae }\end{array}$ \\
\hline $\mathrm{K}_{1}(\% / \mathrm{h})$ & 2,02 & 2,11 & 1,97 & 1,94 \\
$\mathrm{~K}_{2}(\% \mathrm{~h})$ & 4,99 & 5,23 & 4,84 & 4,72 \\
$\mathrm{TMR}_{\mathrm{r}}(\mathrm{h})$ & 49,50 & 47,39 & 50,76 & 51,54 \\
$\mathrm{TMR}_{\mathrm{i}}(\mathrm{h})$ & 20,04 & 19,12 & 20,60 & 21,86 \\
$\mathrm{MR}_{\mathrm{r}} / \mathrm{TMR}_{\mathrm{i}}$ & 2,45 & 2,47 & 2,45 & 2,35 \\
\hline
\end{tabular}

$\mathrm{TMR}_{\mathrm{r},}\left(\mathrm{TMR}_{\mathrm{i}}\right)$ e relação $\mathrm{TMR}_{\mathrm{r}} / \mathrm{TMR}_{\mathrm{i}}\left(R M T_{r,} R M T_{j}\right.$ and $R M T_{r} / R M T_{r}$ ratio).

${ }^{1} 10 \mathrm{~g}$ de Saccharomyces cerevisiae/animal/dia.

coeficientes de digestibilidade da FDN, MS e MO ou vice-versa (Pereira et al., 2001). Como a taxa de passagem é amplamente influenciada pelo tamanho da partícula, que foi o mesmo para todas as dietas, e pelo nível de consumo, que não apresentou diferença significativa entre os tratamentos, os resultados relacionados às digestibilidades estão dentro do esperado, já que, segundo Mertens \& Ely (1982), resíduos indigestíveis são os principais fatores que influenciam o TMR dos alimentos no trato digestório.

A simulação do submodelo relativo ao trato gastrintestinal permitiu mostrar a disponibilidade de proteína metabolizável e do nitrogênio amoniacal ruminal. Na Tabela 5, estão demonstrados os excessos de NAR preditos pelo sistema para as rações experimentais, indicando que não houve sincronização entre carboidratos e proteínas. A concentração de nitrogênio amoniacal ruminal (NAR) é indispensá-

Tabela 5 - Valores preditos para proteína metabolizável (PM-g . kg-1 MS) e disponibilidade de nitrogênio amoniacal ruminal (NAR, $\mathrm{g} \cdot \mathrm{d}^{-1}$ )

Table 5 - Predict values for metabolizable protein (MP- $g$ $\left.\mathrm{kg}^{-1} \mathrm{DM}\right)$ and available ruminal ammonia nitrogen (RAN, $g \cdot d^{-1}$ )

\begin{tabular}{|c|c|c|c|c|}
\hline \multirow[t]{2}{*}{ Item } & \multicolumn{2}{|c|}{$\begin{array}{c}\text { Fontes de NNP } \\
N P N \text { source }\end{array}$} & \multicolumn{2}{|c|}{ S. cerevisiae } \\
\hline & $\begin{array}{l}\text { Uréia } \\
\text { Urea }\end{array}$ & $\begin{array}{c}\text { Cama de frango } \\
\text { Broiler litter }\end{array}$ & $0 \mathrm{~g} / \mathrm{d}$ & $10 \mathrm{~g} / \mathrm{d}$ \\
\hline $\mathrm{PM}^{1}$ & 85,25 & 82 & 83,62 & 82,50 \\
\hline $\mathrm{NAR}^{1}$ & 42,50 & 61 & 51,75 & 45,57 \\
\hline
\end{tabular}

PM (g $\left.\cdot \mathrm{kg}^{-1} \mathrm{MS}\right)$ e NAR $\left(\mathrm{g} \cdot \mathrm{d}^{-1}\right)\left(\mathrm{MP}\left[\mathrm{g} \cdot \mathrm{kg}^{-1} \mathrm{DM}\right]\right.$ and RAN $\left.\left[\mathrm{g} \cdot \mathrm{d}^{-1}\right]\right)$. vel para o crescimento microbiano, desde que associado a fontes de energia, e está diretamente relacionada à solubilidade da proteína dietética e à retenção de N pelo animal (Coelho da Silva \& Leão, 1979). O aumento da disponibilidade de energia, em situações de maior degradação do N, resulta em condição mais favorável do crescimento microbiano e de minimização das perdas nitrogenadas (Nocek \& Russell, 1998); portanto, o fornecimento de fonte de carboidratos facilmente fermentáveis poderia ser uma alternativa para obtenção da sincronização entre a disponibilidade de $\mathrm{N}$ e a degradação de carboidratos, principalmente para as bactérias que degradam carboidratos estruturais, uma vez que estes constituem a principal fonte de energia nas condições dietéticas predominantes no presente estudo. O nitrogênio amoniacal é removido do rúmen pela incorporação à matéria microbiana, pela absorção através do epitélio ruminal e pelo fluido passando para outras partes do trato digestório.

Assim, o relativo fluxo entre esses vários caminhos pode determinar a concentração de amônia em cada tempo. O principal fator que regula a taxa de absorção de amônia através do epitélio ruminal é o pH. O pH mais elevado pode aumentar a proporção de amônia na forma não-ionizada, aumentando sua taxa de absorção (Leng \& Nolan, 1984).

Na Tabela 6, estão expressas as estimativas dos valores observados e preditos para carboidratos totais digeridos no rúmen, fluxo de $\mathrm{N}$ total e $\mathrm{N}$ bact para o abomaso. Constam na Tabela 7 os parâmetros relativos à regressão dos valores observados sobre os preditos. Para as variáveis estudadas, a simulação do 
Tabela 6 - Valores observados e preditos para carboidratos totais digeridos no rúmen (CTDR), fluxo de $\mathrm{N}$ Total para o abomaso (Fluxo $\mathrm{N}$-total) e fluxo de $\mathrm{N}$ bacteriano (fluxo $\mathrm{N}$ bact)

Table 6 - Observed and predicted values for ruminally degradable total carbohydrate (RDTC), abomasal total $N$ flow (total-N flow) and bacterial $N$ flow (Bact $N$ flow)

\begin{tabular}{lcc}
\hline Item & $\begin{array}{c}\text { Valores observados } \\
\text { Observed values }\end{array}$ & $\begin{array}{c}\text { Valores preditos } \\
\text { Predicted values }\end{array}$ \\
\hline CTDR & 2120,61 & 4224,00 \\
Fluxo N-total & 164,66 & 96,64 \\
Fluxo N bact & 60,59 & 74,10 \\
\hline
\end{tabular}

CTDR, Fluxo $\mathrm{N}$-total e fluxo $\mathrm{N}$ bact (RDTC, total- $\mathrm{N}$ flow and Bact $\mathrm{N}$ flow).

Tabela 7 - Estimativas dos parâmetros da regressão dos valores observados sobre os preditos utilizando o modelo $\left(Y=\beta_{1} X\right)$

Table 7 - Estimates of the regression parameters of the observed values on the predicted values using the model $\left(Y=\beta_{1} X\right)$

\begin{tabular}{lcc}
\hline Item & $\begin{array}{c}\text { Viês }\left(\beta_{1}=1\right) \\
\text { Bias }\end{array}$ & $\mathrm{r}^{2}$ \\
\hline CTDR & -49 & 78,00 \\
Fluxo de N total & 1,73 & 95,65 \\
Fluxo de N bact & 0,86 & 86,94 \\
\hline
\end{tabular}

CTDR, Fluxo N-total e fluxo N bact (RDTC, $N$-total flow and Bact $N$ flow).

sistema Cornell resultou em predições que superestimaram em menor grau os CTDR (Tabela 7).

O sistema superestimou ofluxo de N bacteriano no abomaso, possivelmente em virtude da superestimativa dos CTDR. No sistema CNCPS, o rendimento microbiano é estimado em um valor constante de $40 \mathrm{~g}$ de células por kg de carboidratos totais degradados no rúmen (Russell et al., 1992). Estes valores apresentam satisfatória acurácia para elevados fluxos de matéria seca abomasal, que são decorrentes de planos de nutrição superiores do presente estudo e do realizado por Vieira (1998). Quando se trata de baixos níveis de consumo, são preditos valores superestimados para o fluxo de $\mathrm{N}$ bacteriano no abomaso. $\mathrm{O}$ rendimento microbiano pode ser corrigido para o plano de nutrição (AFRC, 1993). O aumento neste último implica em maiores rendimentos, principalmente pela redução da proporção de energia gasta com a manutenção dos microrganismos. É possível que uma correção desta natureza resulte em predições mais acuradas para o crescimento microbiano verificado em animais alimentados com volumosos de baixo valor nutricional.

\section{Conclusões}

O rendimento microbiano não foi influenciado pelas fontes nitrogenadas não-protéicas e pela utilização de Saccharomyces cerevisiae. A validação do sistema Cornell superestimou os carboidratos totais degradados no rúmen, o fluxo de nitrogênio de origem microbiana e subestimou o fluxo de $\mathrm{N}$ total no abomaso.

\section{Literatura Citada}

AGRICULTURAL AND FOOD RESEARCH COUNCIL AFRC. Energy and protein requirements of ruminants. Cambridge: CAB International, Cambridge University Press, 1993. 159p.

AGRICULTURAL RESEARCH COUNCIL - ARC. The nutrient requirements of ruminants livestock. Supp. 1. Commonwealth Agricultural Bureau, Farnham Royal, U.K. 1984.

CECAVA, M.J.; MERCHEN, N.R.; GAY, L.C. et al. Composition of ruminal bacteria harvested from steers as influenced by dietary energy level, feeding frequency and isolation techniques. Journal of Dairy Science, v.73, p.2480-2488, 1990.

CHEN, X.B.; GOMES, M.J. Estimation of microbial protein supply to sheep and cattle basid on urinary excretion of purine derivatives- overview of the technical details. Ocasional publication. Buchsburnd Aberdeen. Ed. Rowett Research Institute, 1992. 21p.

CLARK, J.H.; KLUSMEYER, T.H.; CAMERON, M.R. Microbial protein synthesis and flows of nitrogen fractions to the duodenum of dairy cows. Journal Dairy Science, v.75, p.2304-2323, 1992.

COCHRAN, R.C.; ADAMS, D.C.; WALLACE, J.D. et al. Predicting digestibility diets with internal markers: Evaluation of four potential markes. Journal of Animal Science, v.63, p.1476-14-83, 1986.

COELHO DA SILVA, J.F.; LEÃO, M.l. Fundamentos de nutrição de ruminantes. Piracicaba: Livroceres, 1979. 380p.

DEHORYTY, B.A. Methodology for measuring microbial growth in the rumen. In: SIMPÓSIO INTERNACIONAL SOBRE EXIGÊNCIAS NUTRICIONAIS DE RUMINANTES, 1995, Viçosa, MG. Anais... Viçosa: Universidade Federal de Viçosa, 1995. p.121-138.

FOX, D.G.; SNIFFEN, C.J.; O'CONNOR, J.D. et al. A net carbohydrate and protein system for evaluating cattle diets: III. Cattle requirements and diet adequacy. Journal of Animal Science, v.70, n.12, p.3578-3596, 1992.

FOX, D.G.; BARRY, R.E.; PITT, R.E. et al. Application of the Cornell Net Carbohydrate and Protein model for cattle consuming forages. Journal of Animal Science, v.73, p.267-277, 1995.

GOMES, B.V. Influência das características químicas e físicas das forrageiras sobre o consumo, degradação e cinética da digesta ruminal. Viçosa, MG: Universidade Federal de Viçosa, 1991. 115p. Tese (Doutorado em Zootecnia) Universidade Federal de Viçosa, 1991.

GROVUM, W.L.; WILLIAMS, V.J. Rate of passage of digesta in sheep. 4. Passage of markers through the alimentary tract and the biological relevance, of rate-constants derived from the changes in concentration of marker in faeces. The British Journal of Nutrition, v.30, n.2, p.313-329, 1973. 
LENG, R.A.; NOLAN, V. Nitrogen metabolism in the rumen. Journal of Animal Science, v.67, p.1072-1075, 1984.

MERTENS, D.R.; ELY, L.O. Relationship of rate and extent of digestion to forage utilization - a dynamic model evaluation. Journal of Animal Science, v.54, p.895-905, 1982.

NATIONAL RESEARCH COUNCIL - NRC. Nutrient requirements of dairy cattle. 6.ed. Washington, D.C., 1989. 157p.

NATIONAL RESEARCH COUNCIL - NRC. Nutrients requirements of beef cattle. 7.rev.ed., Washington, D.C.: National Academy Press, 1996. 242p.

NOCEK, J.E.; RUSSELL, J.B. Protein and energy as an integrated system. Relationship of ruminal protein and carbohydrate availability to microbial synthesis and milk production. Journal of Dairy Science, v.71, n.8, p.2070-2107, 1988.

NOLAN, J.V. Nitrogen metabolism by ruminal microorganisms: current understanding and future perspectives. Australian Journal of Agricultural Research, v.47, n.2, p.227-246, 1993.

O'CONNOR, J.D.; SNIFFEN, C.J.; FOX, D.G. et al. A net carbohydrate and protein system for evaluating cattle diets: IV. Predicting amino acid adequacy. Journal of Animal Science, v.71, n.5, p.1298-1311, 1993.

PEREIRA, E.S.; QUEIROZ, A.C.; VALADARES FILHO, S.C. et al. Determinação das frações protéicas e de carboidratos, e taxas de degradação in vitro da cana-de-açúcar e farelo de algodão. Revista Brasileira de Zootecnia, v.29, n.6, p.18871893, 2000.

PEREIRA, E.S.; QUEIROZ, A.C.; VALADARES FILHO, S.C. et al. Fontes nitrogenadas e o uso de Sacharomyces cerevisiae em dietas à base de cana-de-açúcar para novilhos: consumo, digestibilidade, balanço nitrogenado e parâmetros ruminais. Revista Brasileira de Zootecnia, v.30, n.2, p.563-572, 2001.

RUSSELL, J.B.; O’CONNOR, J.D.; FOX, D.G. et al. A Net Carbohydrate and Protein System for evaluating cattle diets. I. Ruminal fermentation. Journal of Animal Science, v.70, n.11, p.3351-3561, 1992.

SNIFFEN, C.J.; O'CONNOR, J.D.; Van SOEST, P.J. et al. A net carbohydrate and protein system for evaluating cattle diets. II - Carbohydrate and protein availability. Journal of Animal Science, v.70, n.11, p.3562-3577, 1992.
STATISCAL ANALYSES SYSTEMS - SAS. User's guide (version 6.03 Ed.). SAS inst. Inc., Cary, NC. 1985.

UDÉN, P.; COLUCCI, P.E.; VAN SOEST, P.J. Investigation of chromium, cerium and cobalt as markers in digesta. Rate of passage studies. Journal of Science and Food Agricultural, v.31, n.3, p.625-632, 1980.

UNIVERSIDADE FEDERAL DE VIÇOSA - UFV. Sistema de análises estatísticas e genética-SAEG. Viçosa, MG: UFV. 1995. (Apostila)

USHIDA, K.; LASSALAS, B.; JOUANY, J.P. Determinations of assay parameters of RNA analysis in bacterial and duodenal samples by spectrophotometry. Influence of sample treatment and preservation. Reproducion and Nutricion Dévelopment, v.25, p.1037-1046, 1985.

VALADARES FILHO, S.C. Eficiência de síntese de proteína microbiana, degradação ruminal e digestibilidade intestinal de proteína bruta, em bovinos. In: SIMPÓSIO INTERNACIONAL SOBRE EXIGÊNCIAS NUTRICIONAIS DE RUMINANTES, 1995, Viçosa, MG. Anais... Viçosa: Universidade Federal de Viçosa, 1995. p.355-388.

Van SOEST, P.J. Nutritional ecology of the ruminant. 2.ed., London: Constock Publishing Associates, 1994. 476p.

Van SOEST, P.J.; ROBERTSON, J.B.; LEWIS, B.A. Methods for dietary fiber, neutral detergent fiber, and nonstarch polysaccharides in relation to animal nutrition. Journal of Dairy Science, v.74, n.10, p.3583-3597, 1991.

VIEIRA, R.A.M. Simulação da dinâmica de nutrientes no trato gastrintestinal: Aplicação e validação de um modelo matemático para bovinos a pasto. Viçosa, MG: Universidade Federal de Viçosa, 1998. 91p. Tese (Doutorado em Zootecnia) - Universidade Federal de Viçosa, 1998. 